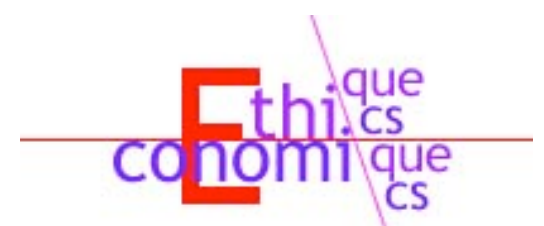

\title{
A Moral Stakeholder Theory of the Firm
}

\author{
\begin{tabular}{l|l} 
By/Par & Daniel Attas \\
\hline & $\begin{array}{l}\text { Hebrew University of Jerusalem } \\
\text { msattas@mscc.huji.ac.il }\end{array}$
\end{tabular}
}

\section{ABSTRACT}

To be a coherent and genuinely alternative conception to the shareholder model, any moral stakeholder theory must meet the following conditions: (1) It must be an ethical theory; (2) It must identify a limited group as stakeholders; (3) The group must be identified on morally relevant grounds; (4) Stakeholder claims must be non-universal; (5) And not held against everyone. A principle for identifying the stakeholder is suggested as a person who has much to lose - financially, socially, or psychologically - by the failure of the firm. The emerging picture contrasts sharply with the conventional conception of the firm. 


\section{THE STATE WE'RE IN}

Stakeholder Theory is in disarray. There is no shortage of Stakeholder (SH) theories proposing distinct ways of perceiving the organization or firm, and diverse outlooks with respect to its ethical obligations. Each theorist and each ethicist has her own proposal of what SH theory requires. Conflicting alternative statements are sometimes advanced by a single figure or Luminary in the Stakeholder Theory literature.

There is at most a very slim shared understanding of what SH theory is all about. In its essence it is a normative method of managing a firm to the benefit of groups and individuals in addition to the shareholders in whose benefit the conventional management model requires that it should be run. ${ }^{1}$ Who might these groups and individuals be? What qualifies them as such? These are questions to which there are no agreed answers. ${ }^{2}$ At times, SH theory is presented as a sophisticated form of (what is confusingly called) enlightened egoism. By considering the harms and benefits to pertinent groups, shareholder interests may indirectly be better advanced than by directly pursuing their interest and ignoring that of relevant others. On some occasions SH theory is offered as a sort of utilitarian checklist: various groups that may be affected by managerial decisions are brought to the attention of the utilitarian managers lest they forget to consider all parties involved. The basis of SH status and the justification of SH management have been offered such diverse grounds as Kantian theory and the right to be treated as an end (Evan and Freeman, 1993; Bowie, 1998), property rights (Donaldson and Preston, 1995), the principle of fairness (Philips, 1997), fiduciary relationships (Goodpaster, 1991), and other contractual arrangements (Freeman and Evan, 1990).

Perhaps SH theory is just a fancy name for ethical concerns that managers should in any case consider even under the alternative shareholder conception of the firm. If that is the case, the concept of a stakeholder turns out to be, theoretically speaking, quite dull. It is no more than a rhetorical device for making explicit and clear to morally insensitive managers what their ethical concerns ought to be under any conception of the firm. But I think that the concept of a stakeholder has the potential to be theoretically fruitful, and require a totally different outlook on what the organization is all about, the kind of relationships within it, and the moral obligations it implies. In this paper I want to investigate what SH theory must be if it is to be a coherent and genuinely alternative conception to the shareholder model.

\footnotetext{
${ }^{1}$ The conventional model, the agency theory of the firm, or what I shall sometimes refer to as the shareholder conception of the firm, views the corporation as its shareholders, and management as their agent. This notion is well entrenched in corporate law, and in the theory of the firm such as that espoused by Ronald Coase in the 1930s and by Jensen and Meckling (1976). It is also implicit in Milton Friedman's notorious view of the social responsibility of business (1979).

${ }^{2}$ For a review of the many ways stakeholders are identified in the literature, see Mitchell, Agle and Wood (1997).
} 


\section{The CONDITIONS For A GENUINE STAKEHOLDER THEORY}

At least five conditions must hold for a proposed theory to supply a coherent basis for generating ethical prescriptions and to count as a genuine alternative to the shareholder model. These are not extracted from existing theories; rather I mean to suggest that they are conceptually required by any such theory. In fact, almost all proposed SH theories fail to meet at least one of the following conditions.

1. It must be an ethical theory. By that I mean that the prescriptions it generates are self-motivating, they are justified for their own sake rather than as instrumental means of advancing one's own interests. If taking account of individuals and groups other than shareholders is justified purely on the grounds that this will advance shareholder interests, then it is far from clear that what is generated here is based on any kind of moral concern at all. ${ }^{3}$ Moreover, whether taking such account will promote shareholder interests, whose account is necessary for this purpose and how much so, are all empirical, i.e., contingent matters. It is very unlikely that a simple rule will identify "stakeholders" and the relative concern that must be shown to them in order to maximise shareholder interests, and that this will not vary with factors that are independent of the stakeholders themselves. This rules out the idea of SH theory as merely instrumental.

2. The theory must identify a limited group as stakeholders and it cannot turn out that practically everyone, no matter how faintly connected to the firm, is to count at one level or another as a stakeholder. This rules out the idea of a utilitarian check list. Everyone, or everyone with the potential of being affected, is in some sense a stakeholder under this conception. Which leads to the absurd notion that competitors too are stakeholders.

3. The stakeholder group must be identified on morally relevant grounds. This rules out the idea that stakeholders are discerned by the power they possess to affect - benefit or harm - the organization, rather than on the basis of some morally relevant trait such as need, desert, entitlement, or special relationship. ${ }^{4}$

4. The kind of claims attributed to stakeholders or the duties owed to them, are not the kind of duties owed universally or the kind of claims persons can make just by the fact that they are persons. Rather they follow from some special status of stakeholders, their unique condition, or the kind of relationship that holds between them and the organization. Whatever duties are owed, they are owed to them qua stakeholders. This rules out the idea that a stakeholder as such is entitled to being treated as an end rather than a mere means. For surely, if this is a valid principle, everyone is entitled to such treatment.

\footnotetext{
${ }^{3}$ I make no claim here about what motivates, or ought to motivate, stakeholder managers in practice. In other words, I'm not insisting that SH theory is an internalist ethical theory.

${ }^{4}$ Freeman, for example, identifies a stakeholder as "any group or individual who can affect or is affected by the achievement of the organizational objectives." (1984:46). As Goodpaster (1991: 59) has shown, Freeman includes those "affected by" the organization only because they may potentially affect it.
} 
5. The kind of claims stakeholders hold, are not held universally against everyone. Rather they follow from the special relationship between stakeholders and the organization or its agents. In other words, duties owed by the firm (or its agents) are not owed by everyone and anyone, rather they are owed by them qua firm agents. This rules out duties such as caring for future generations - whether they count as stakeholders or not. For surely if there is a duty of care towards future generations, everyone is bound by such duties and not merely business or other organizations by virtue of a stakeholder relationship. ${ }^{5}$

It follows from the five conditions that the stakeholder model is based on some kind of special moral relationship between the various stakeholders on the one hand and the organization and its agents (management) on the other. It is on the basis of such a relationship that the parties are obligated towards each other in ways they are not towards others. A relationship such as this can be either contractual - explicitly or implicitly - or noncontractual. The trouble with the contractual view is that whatever contractual aspects exist within stakeholder relationships, any obligations that follow would be fully accounted for by the alternative shareholder model. Thus, if we adopt the contractual understanding of the stakeholder model, we do not really depart from the old shareholder model other than, at most, making explicit whatever implicit contracts already exist. ${ }^{6}$

Thus the special relationship on which the stakeholder model is based must be noncontractual. As such it modifies the organization, delineates insiders and outsiders nonconventionally, and redefines its purposes. If this is a good account of stakeholder theory then, on the one hand, it is hard to see why anyone would think that it is always instrumental to maximising shareholder interests (just one group among stakeholders); and, on the other hand, the idea that it is instrumental to maximising stakeholder interests is trivial.

\section{WHO IS A STAKEHOLDER AND WHY?}

Here's one way of understanding the idea of a stakeholder compatible with the conditions spelled out in the previous section. A stake is a sum of money, or other valuable, wagered on an event. To stake is to wager, to hazard, or to risk. The etymology is uncertain, but probably derives from the idea of fixing or placing on a physical stake, as a sign of commitment (OED). Thus the concept is closely associated with the notions of risk and commitment. The stakeholder is a person who has much to lose - financially, socially, or psychologically from the failure of the firm. This implication can be voluntary - as in the verbs to stake, risk, or wager - and might be exhibited in a commitment made towards the firm. It attaches to people or groups who have tied their own fate to that of the organization. Losses to the firm

\footnotetext{
${ }^{5}$ Of course some businesses may be under greater obligations simply because of their ability to affect - either adversely or positively - future generations. But this doesn't amount to an obligation born of their position as a firm understood to be a locus of stakeholder relationships.

${ }^{6}$ Admittedly, this is a rather sketchy and incomplete argument. For a more thorough critique of the "economic contract" conception of SH theory, see Hendry (2001: 224-226).
} 
entail their own losses. But it can also be non-voluntary - figuratively, being "tied to the stake" - such as in circumstances of reduced possibility of exit. This commitment, whether imposed or willingly undertaken, forms the basis of a moral expectation to be reckoned with.

Who are the various stakeholders in a business organization? Commitment, in so far as it is a state of mind, is inaccessible to observation. We look instead to external signals of such commitment. These are of two kinds: past behaviour of steadiness, risk or cost incurring, and present circumstances of constraint. Thus, we can identify stakeholders by the fact that they have exhibited in their behaviour so far a material commitment to the organization, or that they are in a situation of restricted choice with respect to continuing their relationship with the firm. This entails:

1. Shareholders, but not all of them. To be tied to the notion of risk, it is roughly those shareholders who stand and fall together with the firm. Those who have a substantial portion of their financial assets invested in the firm; or those who have a long term interest in the firm, who do not buy shares for short term gain. These are the people in whose interest the firm must be run. They would have a greater interest in the stability of the firm, in its long term plans, growth and profits, in dividends rather than in fluctuating stock value.

2. Employees, but not all employees. Those who have "been with the firm" for a long part of their career; who have exhibited a commitment to stick with the firm (for example, by willing to go through a firm-specific training course, by refusing offers from other employers, and so on); or who lack alternatives for whatever reason (for example, age, skills, no other employer around, and so forth).

3. The status of suppliers is relevantly similar to that of employees. When a supplier has an exclusive relationship with the firm either voluntarily, or because the firm is in effect a monopsomy, they are clearly stakeholders in the sense advanced here. With the ever growing prevalence of outsourcing the distinction between employee and supplier is in any way blurred.

4. A similar distinction must be made with respect to customers too. Some industries and service sectors are characterised by an ongoing, almost permanent, relationship between customer and organization. The holders of bank accounts, or life insurance, are obvious examples. Readers of daily newspapers might also be a case in point. In some cases customers might lack alternatives due to a monopolistic position of the firm or because high switching costs might be imposed. In other cases the organization might make special efforts to tie the customers to the firm through socalled "loyalty cards", or "frequent flyer" schemes. This kind of relationship confers stakeholder status, but it does not apply equally to casual shoppers in the supermarket, for example.

These four groups, qualified in the way just described, are "insiders" in the moral sense even if the formal legal structure doesn't recognise them as such. They are the stakeholders in whose interest the firm ought to be governed. Within the non-contractual relationship they are the individuals and groups of whom it is fitting to expect some kind of commitment to 
the organization. The principal obligation owed to them is, therefore, one of reciprocating this commitment: an enduring effort at upholding the relationship, of putting the relationship above the benefits that can be derived from it. Stakeholders are not to be substituted for others when that is deemed advantageous for the firm understood as encompassing a partial set of stakeholders.

\section{IMPLEMENTING THE THEORY}

It is the role of management to put the theory into practice. That is to say, to run the firm in the benefit of all its stakeholders. In this sense, as Donaldson and Preston repeatedly point out, SH theory is a managerial theory. "It ... recommends attitudes, structures and practices that, taken together, constitute stakeholder management." (1995: 67) Five steps can be specified as a rough and ready procedure for implementing stakeholder management:

1. Identify the relevant stakeholders. The central marks of stakeholders is their reduced possibility of exit, and their exhibited commitment to the relationship with the firm. Which of the shareholders and employees are genuine stakeholders? Are there suppliers with whom the firm holds such exclusive relationships so that they too should be seen as stakeholders? What sort of product or service does the firm supply, and does it generate the same sort of authentic stakeholder relationship with customers? I do not mean that these questions need to be asked and answered at an individual level ("Tom is a stakeholder, but Harry isn't"), but at a more general level relating to the structure and typical relations the firm has with categories of candidate stakeholders. This will bifurcate the people with whom the organization has any sort of dealings into "insiders" and "outsiders".

2. Assess the strength of the stakeholder claim to special consideration as insiders. Though all stakeholders are members of the organization, and have a legitimate expectation that the firm be run in their interest, it doesn't follow that all have equal SH status. I can only present a crude idea of how SH status may differ. Exhibited commitment is one way in which SH weights may differ, the degree to which exit is inhibited is another: the longer one has been with the firm - whether out of commitment or due to restricted choice - the greater the weight and the claim to be accounted for. This is true not only for employees and suppliers, but for customers and shareholders too. But whereas one can assume that shareholders' weight increases linearly with time; employees' weight may increase exponentially for the greater commitment exhibited with time is compounded with the progressively restricted choice of exit with age.

3. SH interests are to be ascertained. At a first level, the interest common to all stakeholders is the continued existence of the organization and their own status as insiders. Though nothing in the present legal order threatens shareholders in this respect, they have a clear interest that their position as shareholders will not be unilaterally terminated. The same interest pertains to employees, though their position in the present is considerably more precarious. Job security is therefore the 
primary interest of employees. Suppliers and consumers too want to be assured of the permanence of their status, or at least to be safeguarded against a unilateral break off. At a second level come the divergent interests of the different stakeholders. Shareholders would like increased profits. Employees want higher wages but also need workplace safety and hygiene, meaningful work, and so on. Customers are after a fair price, after-purchase service, product safety and so forth.

4. Evaluate priorities among the divergent and, at times, conflicting stakeholder interests or assign weights and aggregate weighted claims so as to achieve a comprehensive solution. This is a hugely important and difficult issue, and I do not want to trivialize it by casually suggesting some priorities or weights. ${ }^{7}$

5. Impose institutional arrangements that would take appropriate account of stakeholder interests. For example, parity membership of the board might lead to adequate representation of the various interests.

But that is not all. After taking due care of insiders, a reminder is in order not to disregard duties towards outsiders. All persons whether insiders or outsiders, in a stakeholder model or in a conventional managerial model, have a right against non-harm, and a right to fair trade, that is to say, to engage in non-coercive, non-deceptive, and non-exploitative commercial transactions.

\section{CONCLUSION}

The picture sketched above contrasts sharply with the conventional conception of the firm. It demarcates the boundaries of the business organization in a novel way. Identifying some conventional outsiders as insiders, and relegating some insiders of the conventional model to the position of outsiders. The model proposed here might be considered depreciatively utopian, in the sense of unrealisable. For it requires a major shift in the way the law, management, and the public at large view the firm and its responsibilities. I cannot gauge the likelihood to which such a shift might occur. I insist, however, that if the term "stakeholder theory" is to stand for a truly different kind of firm, and not a mere semantic beautification of a morally deficient conventional idea, then a conception not very different from the one proposed here should be kept in mind. ${ }^{8}$

\footnotetext{
${ }^{7}$ Hosseini and Brenner (1992), though oddly lacking any moral basis, is one proposed method to generate such values.

${ }^{8}$ I would like to thank Avner de-Shalit, Axel Gosseries, Mark Schwartz, and two anonymous referees for their helpful comments. Research for this paper has benefited from the financial assistance of the Recanati Foundation.
} 


\section{REFERENCES}

BowIE, Norman E. (1998) “A Kantian Theory of Capitalism”, Business Ethics Quarterly special issue 1 pp. 37-60.

Donaldson, T. and Preston, L. E. (1995) "The Stakeholder Theory of the Corporation: Concepts, Evidence and Implications", Academy of Management Review 20 pp. 65-91.

Evan, W. M. and Freeman, R. E.. (1993) "A Stakeholder Theory of the Modern Corporation: Kantian Capitalism" in Beauchamp, T. L. and N. E. Bowie (eds.), Ethical Theory and Business, $4^{\text {th }}$ edition, Prentice Hall, Englewood Cliffs NJ,.

FrEemAN, R. E. and EvAN, W. M. (1990). "Corporate Governance: A Stakeholder interpretation" Journal of Behavioral Economics 19: 337-359.

FrIEDMAN, M. (1979). "The Social Responsibility of Business Is to Increase Its Profit", The New York Times Magazine (September 13).

Goodpaster, K. E. (1991) "Business Ethics and Stakeholder Analysis" Business Ethics Quarterly 1 pp. 53-73.

Hosseini, J. C. and BREnNER, S. N. (1992)"A Stakeholder Theory of the Firm: A Methodology to Generate Value Matrix Weights”, Business Ethics Quarterly 2 pp. 99-119.

Jensen, M. C. and Meckling, W. H. (1976). "Theory of the firm: Managerial behavior, agency costs and ownership structure", Journal of Financial Economics 3 pp. 305-360.

Mitchell, R.K., Agle, B.R. and Wood, D.J. (1997). "Toward a Theory of Stakeholder Identification and Salience: Defining the Principle of Who and What Really Counts", Academy of Management Review 22 pp. 853-886.

PHILIPS, R. A. (1997). "Stakeholder Theory and a Principle of Fairness", Business Ethics Quarterly 7 pp. 51-66. 